Gynaecologia 1963;156:400

\title{
Kongresskalender
}

\section{COMING MEDICAL MEETINGS TABLEAU DES CONGRÈS}

Die 64. Tagung der Nordwestdeutschen Gesellschaft für Gynäkologie findet vom 23. bis 24. Mai 1964 in Lübeck statt. Vorsitzender: Prof. W. v. Massenbach, 24 Lübeck, Städt. Frauenklinik.

Referate: Die Gefährdung des menschlichen Keimlings bei Viruserkrankungen der Mutter in der Frühschwangerschaft (Prof. Dr. G. Töndury, Zurich); Niere und Schwangerschaft (Prof. Dr. A. Kleinschmídl, Lübeck); Leber und Schwangerschaft (Prof. Dr. H. A. Kühn, Lübeck).

A. Anmeldungen von Vorträgen zu den Referaten und von freien Vorträgen wer-den bis zum 15. März 1964 an den 2. Schriftführer, Oberarzt Dr. J. Hahn, 24 Lübeck, Ratzeburger Allee 160, Frauenklinik, erbeten. 